\title{
Transection of the Retrohepatic Vena Cava in a Case of Total Situs Inversus Following Blunt Trauma
}

Sqn Ldr D J Jones, MB, FRCS, RAF Consultant Surgeon

The Princess of Wales Royal Air Force Hospital Ely Cambs CB6 1DN

\section{Sqn Ldr R E O Daum}

MB, FFARCS, RAF Consultant Anaesthetist

The Princess Mary Hospital Royal Air Force Akrotiri, BFPO 57

SUMMARY: Total transection of the retrohepatic inferior vena cava from blunt trauma is a rare and usually fatal injury. Such an injury in a patient with total situs inversus and previous surgical correction of great vessel transposition is described. A possible mechanism for the injury is suggested.

\section{Case Presentation}

A 13 year old male was admitted to hospital one hour after being struck on the left side by a van travelling at $20 \mathrm{mph}$. Initial examination showed him to be conscious, orientated and shocked with a blood pressure of $90 /$ $60 \mathrm{~mm} \mathrm{Hg}$ and a pulse of $120 /$ minute. The only external injury was a laceration on the left temple. Left abdominal tenderness was present. The boy's mother stated that her son had total situs inversus, had undergone surgical correction for transposition of the great vessels at the age of one year, since when he had been well.

$\mathrm{X}$-rays confirmed the situs inversus, and revealed a left pneumothorax but no bony injuries. Ultrasound demonstrated free fluid in the abdomen and suggested damage to the left lobe of the liver which, of course, was the larger in this case. Resuscitation was begun with colloid and crystalloid and a chest drain was inserted. He was taken to theatre and a laparotomy was performed. Approximately 1.5 litres of blood was aspirated from the abdomen, and the lateral half of the left lobe of the liver was found to be very extensively lacerated. There was also a small retroperitoneal haematoma. There appeared to be no other injuries and a left hemihepatectomy was begun. During mobilisation of the liver, torrential haemorrhage occurred from the retrohepatic region. The source for this was found to be a completely transected inferior vena cava (IVC) at the level of the diaphragm. Despite packing, massive blood transfusion, control of haemorrhage with balloon catheters, and thoracotomy in an attempt to gain control of the thoracic IVC, the heart arrested and subsequent resuscitation was unsuccessful. A post mortem confirmed the operative findings and also revealed dense adhesions between the inferior surface of the heart and diaphragm. These adhesions completely encased the thoracic IVC.

\section{Discussion}

Injuries to the IVC have a high mortality rate.
Predictors of poor survival are blunt trauma, the presence of shock on admission, retro-hepatic injury and the presence of injury to other organs . This case fulfils all of these criteria. Mortality rates of $75-100 \%$ have been quoted for such injuries.

Reports from major trauma centres suggest that the mainstays of treatment are full and adequate resuscitation, recognition of the injury, proximal and distal control of the IVC and, if necessary, thoracotomol o to control the intra pericardial IVC, with subsequers o bypass and isolation of the injured segment ${ }^{1,3,4}$. Othe reports have suggested the use of balloon catheters ta control haemorrhage with transfusion of blood through $\infty$ the proximal catheter to increase venous return ${ }^{2}$.

Nearly all reports stress the importance of good transfusion facilities and quote replacement bloog volumes as high as 30 units ${ }^{1,3,4}$. Small district generäl hospitals do not hold large stores of bank blood and the use of autologous transfusion devices could be of great value in this situation.

The site of this injury (at the level of the diaphragm) made local control impossible. Control via a thoracotomy proved unsuccessful due to the adhesions around the previous operation site. It should be noted that thoracotomy, even for the initial correction of great vessel transposition, is often made difficult by the inaccessibility of the IVC, and does not always allow precise control ${ }^{5}$. It is not surprising therefore that difficulty was experienced in this case.

The post mortem findings suggest that the injury to the IVC was caused by shearing forces between the mass of adhesions binding it to the heart and diaphragm and its delicate and relatively immobile infradiaphragmatic portion.

\section{Conclusion}

Early recognition of these injuries, massive transfusion and the availability of adequate bypass facilities are the major means by which the high mortality of retro-hepatic caval injuries can be reduced. 


\section{REFERENCES}

1. MillikAN $J$ S, et al. Inferior vena cava injuries - a continuing challenge. J Trauma $1983 ; 23: 207$.

2. Ravikumar S and StaHL W M. Intra luminal balloon catheter occlusion for major vena cava injuries. J Trauma $1985 ; 25$ : 458.

3. MCMaster P and Tooley M. Management of inferior vena caval injury in liver trauma. Ann $R$ Coll Surg Engl

4. MCMASTER P. Hepatic trauma involving the hepatic veins and vena cava. Injury 1976; 7: 299.

5. WATSON D C, et al. Surgical approach to corrected transposition of the great vessels and situs inversus $(I, D, D)$ with ventricular septal defect and systemic atrio ventricular valve regurgitation. Ann Thorac Surg 1984; 38: 520 . 1977; 59: 502. 